\title{
Modeling and Simulation of Bldc Motor for Aiding and Opposing Loads
}

\author{
Swathi Kumari. A ${ }^{1,}$ Y. Laxminarayana ${ }^{2,}$ Dr. S. Tarakalyani ${ }^{3}$ \\ M.Tech Student, Scientist-D, DRDO, Professor \\ 1, 3 Department of Electrical and Electronics Engineering, JNTUCE, Hyderabad, India. \\ 2 Control Systems Laboratory, DRDO.
}

\begin{abstract}
BLDC (Brushless DC) motors have found a wide range of applications in industrial automation, automotive, aerospace, instrumentation because of their long operating life, compact form, reliability and low maintenance, high efficiency and better speed torque characteristics. This Paper is an endeavor towards developing a simulink model with the parameters of a real trapezoidal back-emf type of BLDC motor. The model is then analyzed under aiding and opposing loads.. The variations in motor speed-torque characteristics, back emf and current drawn by the motor for both no-load and loaded (aiding and opposing loads) conditions is analyzed. Some experimental tests are conducted to analyze the model and compared with the simulation results which are very useful in studying the performance of motor system.
\end{abstract}

Key words: Brushless direct current (BLDC) motor, trapezoidal back-emf, SIMULINK / MATLAB.

\section{Back Ground:}

BLDC motor is similar to a DC motor in performance but without brushes. It is a new kind of Motor which quickly maturated with the development of the power electronics and high flux density permanent magnetic materials. Recent research [1] has indicated that the permanent magnet motor drives, which include the permanent magnet synchronous motor (PMSM) and the brushless de motor (BLDCM) could become serious competitors to the induction motor for servo applications. Many papers and journals have been published on BLDC motors regarding the operation, speed control methods and so on. In many researches modeling and simulation of BLDC motor has done and is used for many of the applications. In this paper the BLDC motor back emf, speed vs. torque characteristics and current waveforms for two different types of loadings i.e., aiding and opposing loads and also the characteristics at no load condition are presented. A real trapezoidal type BLDC motor is modeled, analyzed and simulated in MATLAB/ SIMULINK and the same is tested on an existing motor and the valuations are tabulated.

\section{Introduction:}

Brushless DC motors (BLDC motors) also known as electronically commutated motors are powered by direct-current (DC) electricity and having electronic commutation systems rather than mechanical commutator and brushes. BLDC motors are one of the motor types rapidly gaining popularity. BLDC motors have many advantages like simple structure, reliable operation, low maintenance, high dynamic speed, better control performance and excellent mechanical properties. The Brushless DC Motor consists of a rotating rotor with rare earth magnets and a stator. Brushless DC Motors are considered to be an "inside-out" version of a Brushed DC Motor; the commutator and brushes are nonexistent, and the windings are located externally, connected to the controller. There are typically two different construction types for the Brushless DC Motor: Inrunner and Outrunner configurations.

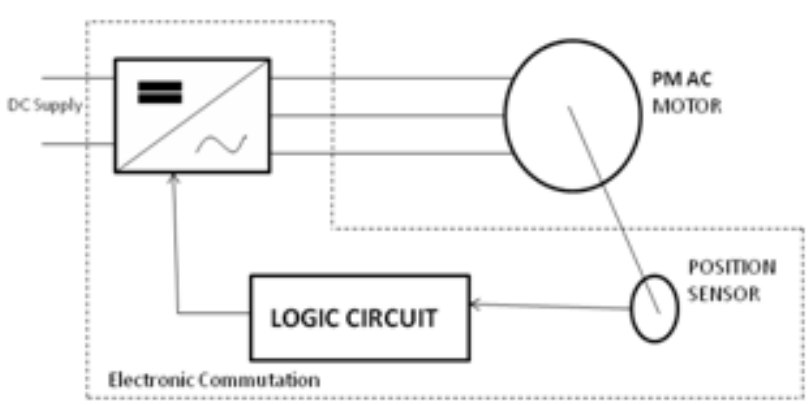

Figure 1 Block diagram of BLDC Motor 
The block diagram of BLDC motor is shown in Fig 1. It is a combination of permanent magnet synchronous motor along with electronic commutator unit. It consists of position sensors, logic circuit and universal inverter bridge.

\section{System Model:}

A Brushless dc motor has a rotor with permanent magnets and a stator with windings connected to the control electronics. The control electronics replace the function of the commutator and energize the proper winding. Once the windings are energized stator winding leads the rotor magnet, and switches just as the rotor aligns with the stator. Each commutation sequence has one of the windings energized to positive power (current enters into the winding), the second winding is negative (current exits the winding) and the third is in a nonenergized condition. Torque is produced because of the interaction between the magnetic field generated by the stator coils and the permanent magnets. Ideally, the peak torque occurs when these two fields are at $90^{\circ}$ to each other and falls off as the fields move together. In order to keep the motor running, the magnetic field produced by the windings should shift position, as the rotor moves to catch up with the stator field. Six-step commutation is a cost-effective means of electronic commutation, due to the simple and relatively inexpensive feedback and drive devices.

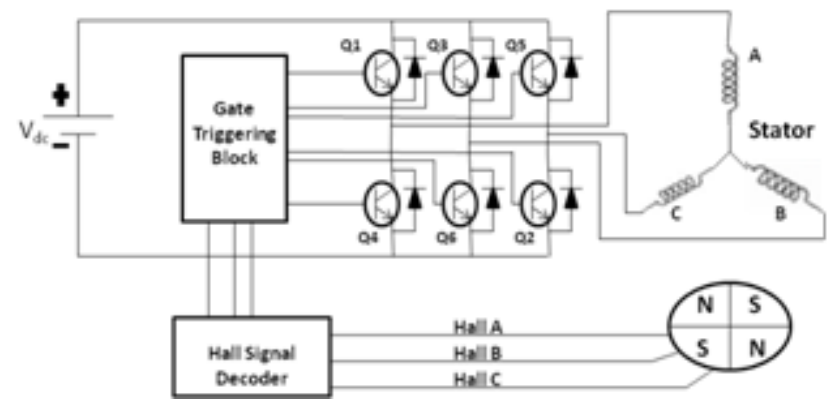

Figure 2 Schematic system of BLDC motor drive

In this system, Hall Effect sensors produce signals according to rotor position for commutation. Also a 3-phase inverter using MOSFETs/IGBTs is used as voltage source. Different control techniques can be applied to the model. As shown in Fig.2 simulation model is consisting of four parts, such as BLDC motor, hall decoder, gate triggering block and 3-phase universal bridge.

Each part is modeled separately and integrated in overall simulation model. BLDC motor is modeled using electrical and mechanical mathematical equations. For Hall decoding block and gate triggering block logical models are developed according to hall signals (rotor position).

\section{BIdc Motor Model:}

In this section the mathematical modeling of a three-phase, four- pole, star-connected trapezoidal backemf type BLDC motor is presented. The PMSM has a sinusoidal back emf and requires sinusoidal stator currents to produce constant torque while the BLDCM has a trapezoidal back emf and requires rectangular stator currents to produce constant torque. Some confusion exists, both in the industry and in the university research environment, as to the correct models that should be used in each case. The PMSM is very similar to the standard wound rotor synchronous machine except that the PMSM has no damper windings and excitation is provided by a permanent magnet instead of a field winding. Hence the d, q model of the PMSM can be derived from the well-known model of the synchronous machine with the equations of the damper windings and field current dynamics removed.

As is well known, the transformation of the synchronous machine equations from the abc phase variables to the $\mathrm{d}$, $\mathrm{q}$ variables forces all sinusoidal varying inductances in the abc frame to become constant in the $\mathrm{d}$, q frame. In the BLDCM motor, since the back emf is no sinusoidal, the inductances do not vary sinusoidal in the abc frame and it does not seem advantageous to transform the equations to the $\mathrm{d}$, $\mathrm{q}$ frame since the inductances will not be constant after transformation. Hence it is proposed to use the abc phase variables model for the BLDCM. Trapezoidal back-emf is referring that its voltage and current waveforms are trapezoidal in nature. With the intention of simplifying equations and overall model the following assumptions are made:

a. All the stator phase windings are symmetrical and concentrated, hence stator resistance, inductances are constant and equal.

b. Hysteresis and eddy current losses are eliminated and magnetic saturation is ignored.

c. Armature Reaction is not considered. 
Under the above assumptions, the circuit equations of a BLDC motor can be represented as in equation (13). Here ea, eb, ec are the trapezoidal back EMF's as shown in Fig.3

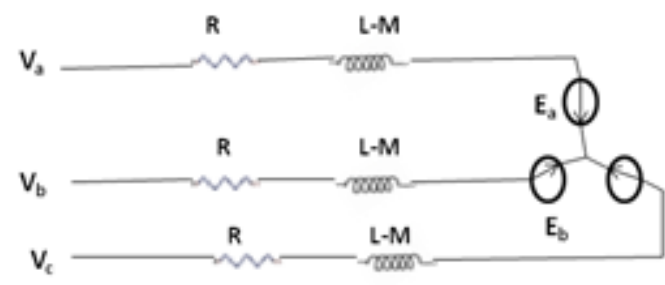

Figure 3 Electrical Circuit of BLDC Motor

The mathematical equations of BLDC motor are:

$$
\begin{aligned}
& V_{a}=R i_{a}+(L-M) \frac{d i_{a}}{d t}+E_{a} \\
& V_{b}=R i_{b}+(L-M) \frac{d i_{b}}{d t}+E_{b} \\
& V_{c}=R i_{c}+(L-M) \frac{d i_{c}}{d t}+E_{c}
\end{aligned}
$$

The back-EMFs and electromagnetic torques can be expressed as:

$$
\begin{aligned}
& \left\{\begin{array}{l}
\mathrm{E}_{\mathrm{a}}=\frac{\mathrm{K}_{\mathrm{e}}}{2} \omega_{\mathrm{m}} \mathrm{F}\left(\theta_{\mathrm{e}}\right) \\
\mathrm{E}_{\mathrm{b}}=\frac{\mathrm{K}_{\mathrm{e}}}{2} \omega_{\mathrm{m}} \mathrm{F}\left(\theta_{\mathrm{e}}-\frac{2 \pi}{3}\right) \\
\mathrm{E}_{\mathrm{c}}=\frac{\mathrm{K}_{\mathrm{e}}}{2} \omega_{\mathrm{m}} \mathrm{F}\left(\theta_{\mathrm{e}}+\frac{2 \pi}{3}\right)
\end{array}\right. \\
& \left\{\begin{array}{l}
\mathrm{T}_{\mathrm{a}}=\frac{\mathrm{K}_{\mathrm{t}}}{2} \mathrm{i}_{\mathrm{a}} \mathrm{F}\left(\theta_{\mathrm{e}}\right) \\
\mathrm{T}_{\mathrm{b}}=\frac{\mathrm{K}_{\mathrm{t}}}{2} \mathrm{i}_{\mathrm{b}} \mathrm{F}\left(\theta_{\mathrm{e}}-\frac{2 \pi}{3}\right) \\
\mathrm{T}_{\mathrm{c}}=\frac{\mathrm{K}_{\mathrm{t}}}{2} \mathrm{i}_{\mathrm{c}} \mathrm{F}\left(\theta_{\mathrm{e}}+\frac{2 \pi}{3}\right)
\end{array}\right. \\
& \mathrm{Te}=\frac{\mathrm{Kt}}{2}\left(\mathrm{i}_{\mathrm{a}} \mathrm{F}\left(\theta_{\mathrm{e}}\right)+\mathrm{i}_{\mathrm{b}} \mathrm{F}\left(\theta_{\mathrm{e}}-\frac{2 \pi}{3}\right)+\mathrm{i}_{\mathrm{c}} \mathrm{F}\left(\theta_{\mathrm{e}}+\frac{2 \pi}{3}\right)\right)
\end{aligned}
$$

The electrical angle $\theta_{\mathrm{e}}$ is equal to the rotor angle times the number of pole pairs,

$$
\begin{aligned}
& \theta_{\mathrm{e}}=\frac{\mathrm{P}}{2} \theta_{\mathrm{m}} \\
& \omega_{\mathrm{m}}=\frac{\mathrm{d} \theta_{\mathrm{m}}}{\mathrm{dt}}
\end{aligned}
$$

Where $\mathrm{k}=\mathrm{a}, \mathrm{b}, \mathrm{c}$

$\mathrm{V}_{\mathrm{k}}: \mathrm{k}^{\text {th }}$ Phase voltage applied from inverter to BLDC

$\mathrm{i}_{\mathrm{k}}: \mathrm{k}^{\text {th }}$ Phase current

R: Resistance of each phase of BLDC

$\mathrm{L}$ : Inductance of each phase of BLDC

M: Mutual inductance

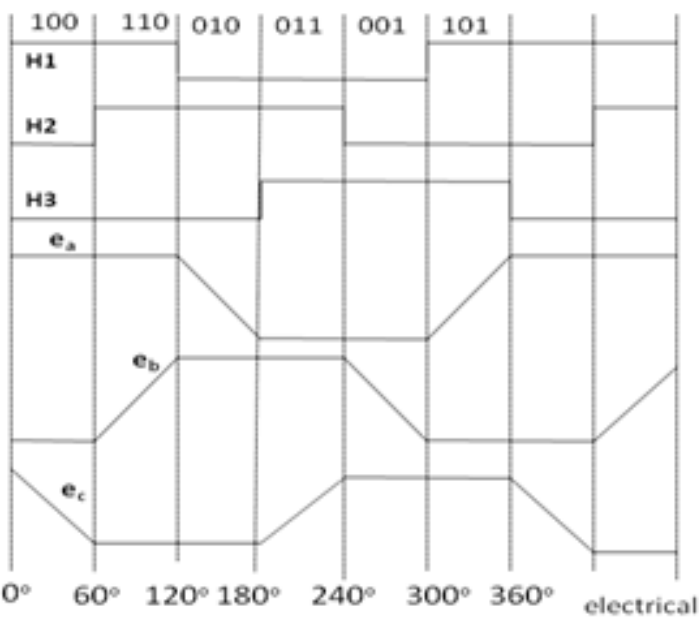

Fig. 4 Hall sensor signals and back EMF wave forms $\mathrm{E}_{\mathrm{k}}: \mathrm{k}^{\text {th }}$ Phase back $-\mathrm{EMF}$ 
$\mathrm{T}_{\mathrm{k}}$ : Electric torque produced by $\mathrm{k}_{\mathrm{th}}$ phase

$\mathrm{T}_{\mathrm{e}}$ : Electric torque produced by BLDC

J: Rotor inertia

$\beta$ : Friction constant

$\mathrm{K}_{\mathrm{e}}$ : Back - EMF constant

$\mathrm{K}_{\mathrm{t}}$ : Torque constant

$\omega_{\mathrm{m}}:$ Angular speed of rotor

$\theta_{\mathrm{m}}$ : Mechanical angle of rotor

$\theta_{\mathrm{e}}$ : Electrical angle of rotor

$\mathrm{F}\left(\theta_{\mathrm{e}}\right)$ : Back - EMF reference as function of rotor position

The function $\mathrm{F}\left(\theta_{\mathrm{e}}\right)$ gives trapezoidal waveform of back EMF as shown in Fig 4. One period of function can be written as,

$$
\mathrm{F}\left(\theta_{\mathrm{e}}\right)=\left\{\begin{array}{lc}
1 & 0<\theta_{\mathrm{e}}<\frac{2 \pi}{3} \\
1-\frac{6}{\pi}\left(\theta_{\mathrm{e}}-\frac{2 \pi}{3}\right) & \frac{2 \pi}{3}<\theta_{\mathrm{e}}<\pi \\
-1 & \pi<\theta_{\mathrm{e}}<\frac{5 \pi}{3} \\
-1+\frac{6}{\pi}\left(\theta_{\mathrm{e}}-\frac{5 \pi}{3}\right) & \frac{5 \pi}{3}<\theta_{\mathrm{e}}<2 \pi
\end{array}\right.
$$

Hence it is assumed that phase zones are distributed symmetrically to different phase windings, backEMF signals have 120 degree phase shift with respect to each other. For convenient implementation in Matlab/Simulink, equations (1-3) and (7) must be written in state space form. Since each voltage equation is a linear combination of the other two voltage equations only two equations are needed.

State space form of equations (1), (2), (3) and (7) can be derived as:

$V_{a b}=R\left(i_{a}-i_{b}\right)+(L-M) \frac{d}{d t}\left(i_{a}-i_{b}\right)+E_{a b}(11)$
$V_{b c}=R\left(i_{b}-i_{c}\right)+(L-M) \frac{d}{d t}\left(i_{b}-i_{c}\right)+E_{b c}(12)$

Where $\mathrm{i}_{\mathrm{a}}+\mathrm{i}_{\mathrm{b}}+\mathrm{i}_{\mathrm{c}}=0$, therefore after modifying equations (11) and (12) and neglecting mutual inductance,

$\frac{\mathrm{di}_{\mathrm{a}}}{\mathrm{dt}}=-\frac{\mathrm{R}}{\mathrm{L}} \mathrm{i}_{\mathrm{a}}+\frac{2}{3 \mathrm{~L}}\left(\mathrm{~V}_{\mathrm{ab}}-\mathrm{E}_{\mathrm{ab}}\right)+\frac{1}{3 \mathrm{~L}}\left(\mathrm{~V}_{\mathrm{bc}}-\mathrm{E}_{\mathrm{bc}}\right)$

$\frac{d i_{b}}{d t}=-\frac{R}{L} i_{b}-\frac{1}{3 L}\left(V_{a b}-E_{a b}\right)+\frac{1}{3 L}\left(V_{b c}-E_{b c}\right)$

Then state space model of BLDC motor is:

$$
\begin{aligned}
& {\left[\begin{array}{c}
\mathrm{i}_{\mathrm{a}} \\
\mathrm{i}_{\mathrm{b}} \\
\omega_{\mathrm{m}}
\end{array}\right]=\left[\begin{array}{ccc}
-\frac{\mathrm{R}}{\mathrm{L}} & 0 & 0 \\
0 & -\frac{\mathrm{R}}{\mathrm{L}} & 0 \\
0 & 0 & -\frac{\beta}{\mathrm{J}}
\end{array}\right]\left[\begin{array}{c}
\mathrm{i}_{\mathrm{a}} \\
\mathrm{i}_{\mathrm{b}} \\
\omega_{\mathrm{m}}
\end{array}\right]+\left[\begin{array}{ccc}
\frac{2}{3 L} & \frac{1}{3 L} & 0 \\
-\frac{1}{3 L} & \frac{1}{3 L} & 0 \\
0 & 0 & \frac{1}{\mathrm{~J}}
\end{array}\right]\left[\begin{array}{c}
\mathrm{v}_{\mathrm{ab}}-\mathrm{E}_{\mathrm{ab}} \\
\mathrm{V}_{\mathrm{bc}}-\mathrm{E}_{\mathrm{bc}} \\
\mathrm{T}_{\mathrm{e}}-\mathrm{T}_{1}
\end{array}\right]_{(15)}} \\
& {\left[\begin{array}{c}
\mathrm{i}_{\mathrm{a}} \\
\mathrm{i}_{\mathrm{b}} \\
\mathrm{i}_{\mathrm{c}} \\
\omega_{\mathrm{m}}
\end{array}\right]=\left[\begin{array}{ccc}
1 & 0 & 0 \\
0 & 1 & 0 \\
-1 & -1 & 0 \\
0 & 0 & 1
\end{array}\right]\left[\begin{array}{c}
\mathrm{i}_{\mathrm{a}} \\
\mathrm{i}_{\mathrm{b}} \\
\omega_{\mathrm{m}}
\end{array}\right]}
\end{aligned}
$$

Implementing of final state space equations (15) and (16) will make model more complex. Although neutral point of motor is not accessible but virtually is possible to estimate it with zero crossing point of backEMF. Also for linear and zero initial condition systems, State space to Laplace transform and vice versa can be written. Therefore final state space equation is divided to two simple and separate electrical and mechanical Laplace equations applied by phase to neutral voltages.

By applying Laplace transformations to equations (1-3) and (7), we get electrical equations of BLDC motor:

$\mathrm{V}_{\mathrm{a}}(\mathrm{s})-\mathrm{E}_{\mathrm{a}}(\mathrm{s})=(\mathrm{sL}+\mathrm{R}) \mathrm{I}_{\mathrm{a}}(\mathrm{s})$

$V_{b}(s)-E_{b}(s)=(s L+R) I_{b}(s)$

$V_{c}(s)-E_{c}(s)=(s L+R) I_{c}(s)$

Mechanical equation of BLDC motor:

$\mathrm{T}_{\mathrm{e}}(\mathrm{s})-\mathrm{T}_{1}(\mathrm{~s})=(\mathrm{s} J+\beta) \omega_{\mathrm{m}}(\mathrm{s})$ 
It makes the BLDC motor model more simple and convenient for various control techniques implementation. Ideal reference back-EMF signal of motor is also produced according to the electrical rotation of rotor in each phase separately and applied as negative feedback to phase voltage. The parameters used for the modeling BLDC motor is shown in table 1. The parameters are taken from the datasheet of a BLDC motor designed by author (2).

\begin{tabular}{|l|l|}
\hline Motor data & Value \\
\hline Stator Inductance/ph & $200 \mu \mathrm{H}$ \\
Stator Resistance/ph & $0.55 \Omega$ \\
Number of Poles & 8 \\
Nominal Voltage & $28 \mathrm{~V}$ \\
Assigned Power Rating & $280 \mathrm{~W}$ \\
No-load speed & $13000 \mathrm{rpm}$ \\
Rated Speed & $6000 \mathrm{rpm}$ \\
\hline
\end{tabular}

Table 1 BLDC motor parameters

The overall simulink model of the BLDC Motor is shown in below fig. 5. The model consists of several sub-blocks viz,

- BLDC motor block.

- Hall decoder block

- Gate triggering block

- Inverter block.

The output scopes are provided for hall signals, speed, and torque, current and 3-phase back-EMF signals. The input scopes (Vdc, Vdc1) are provided for measuring the input voltages at the MOSFET inverter bridge and at the BLDC motor input. The load torque is applied in the form of step signals at the BLDC motor input terminal.

\section{BLDC Motor Block:}

From the Laplace equations (17-20), the BLDC motor modeled in MATLAB/ Simulink. It consists of four input ports and five output ports. The output port consists of hall signals, speed, and torque, current and back-EMF

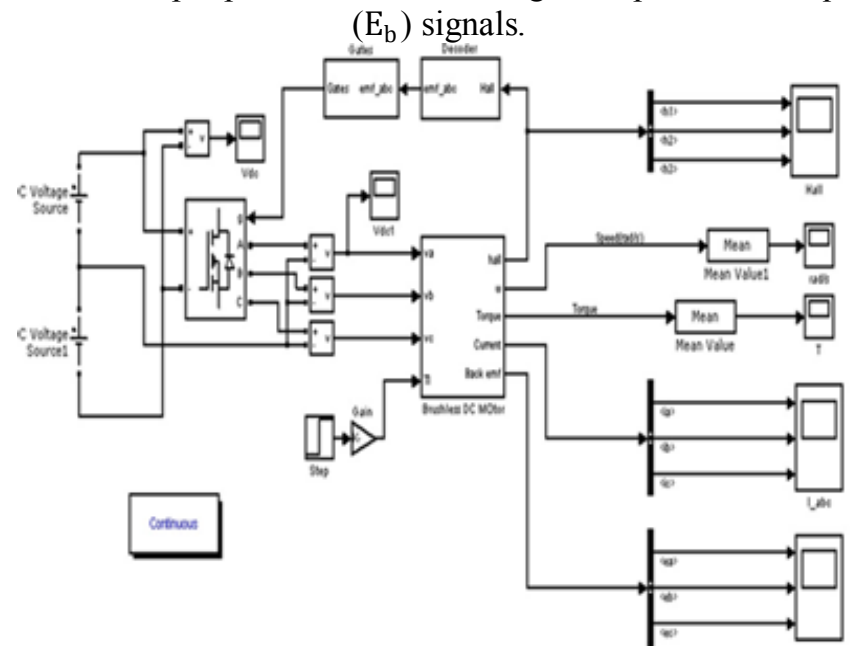

Fig. 5 Overall Model of BLDC Motor

\section{Hall Decoder Block:}

Hall Effect signals of motor are produced according to the rotor position.

\begin{tabular}{|c|c|c|c|c|c|}
\hline $\begin{array}{c}\text { Hall Sensor } \\
\mathbf{H a}\end{array}$ & $\begin{array}{c}\text { Hall Sensor } \\
\mathbf{H b}\end{array}$ & $\begin{array}{c}\text { Hall Sensor } \\
\mathbf{H c}\end{array}$ & $\begin{array}{c}\text { Back-EMF Phase A } \\
\left(\mathbf{e}_{\mathbf{a}}\right)\end{array}$ & $\begin{array}{c}\text { Back-EMF Phase B } \\
\left(\mathbf{e}_{\mathbf{b}}\right)\end{array}$ & $\begin{array}{c}\text { Back-EMF Phase C } \\
\left(\mathbf{e}_{\mathbf{c}}\right)\end{array}$ \\
\hline 1 & 0 & 0 & +1 & -1 & 0 \\
\hline 1 & 1 & 0 & +1 & 0 & -1 \\
\hline 0 & 1 & 0 & 0 & +1 & -1 \\
\hline 0 & 1 & 1 & -1 & +1 & 0 \\
\hline 0 & 0 & 1 & -1 & 0 & +1 \\
\hline 1 & 0 & 1 & 0 & -1 & +1 \\
\hline
\end{tabular}

Table 2 Hall Decoder truth table 
Table 2 shows the truth table in between Hall Signals and the back-EMFs. According to a particular rotor position hall sensor signals are produced and for the respective hall signal its corresponding back-EMF can be decoded.

From the truth table Boolean equations for back-EMFs for all three phases can be written as the following:

For Phase A: $\quad+\mathrm{e}_{\mathrm{a}}=\mathrm{H}_{\mathrm{a}} \overline{\mathrm{H}_{\mathrm{c}}} \quad$ and $-\mathrm{e}_{\mathrm{a}}=\overline{\mathrm{H}_{\mathrm{a}}} \mathrm{H}_{\mathrm{c}}$

For Phase B: $\quad+\mathrm{e}_{\mathrm{b}}=\overline{\mathrm{H}_{\mathrm{a}}} \mathrm{H}_{\mathrm{b}} \quad$ and $-\mathrm{e}_{\mathrm{b}}=\mathrm{H}_{\mathrm{a}} \overline{\mathrm{H}_{\mathrm{b}}}$

For Phase $\mathrm{C}$ : $\quad+\mathrm{e}_{\mathrm{c}}=\overline{\mathrm{H}_{\mathrm{b}}} \mathrm{H}_{\mathrm{c}} \quad$ and $-\mathrm{e}_{\mathrm{c}}=\mathrm{H}_{\mathrm{b}} \overline{\mathrm{H}_{\mathrm{c}}}$

\section{Gate Triggering Block:}

The implementation of the following truth table 3, at every instant two phases are conducting one phase +ve and other phase -ve. Hence its corresponding switches will be triggered as per the given truth table 3 .

\begin{tabular}{|c|c|c|c|c|c|c|c|c|}
\hline Ea & Eb & Ec & Q1 & Q2 & Q3 & Q4 & Q5 & Q6 \\
\hline+1 & -1 & 0 & 1 & 0 & 0 & 1 & 0 & 0 \\
\hline+1 & 0 & -1 & 1 & 0 & 0 & 0 & 0 & 1 \\
\hline 0 & +1 & -1 & 0 & 0 & 1 & 0 & 0 & 1 \\
\hline-1 & +1 & 0 & 0 & 1 & 1 & 0 & 0 & 0 \\
\hline-1 & 0 & +1 & 0 & 1 & 0 & 0 & 1 & 0 \\
\hline 0 & -1 & +1 & 0 & 0 & 0 & 1 & 1 & 0 \\
\hline
\end{tabular}

Table 3 Gate signal truth table

block.

The outputs obtained from the decoder block i.e. $e_{a}, e_{b}, e_{c}$, are given as inputs to the gate triggering

\section{Inverter Block:}

The inverter supplies the input voltage for the three phases of the BLDC motor. It comprises of two power semiconductor devices on each phase leg. Appropriate pairs of MOSFET's (Q1 to Q6) are driven based on the hall sensors input. Three phases are commutated for every $60^{\circ}$. As sensors are the direct feed back of the rotor position, synchronization between stator and rotor flux is achieved.

\section{Simulation Results:}

The performance of the developed BLDC motor model is examined using motor parameters as listed in Table 1, under the following conditions the motor performance has been simulated and analyzed:

- No-load performance.

- Motor under opposing load condition.

- Motor under aiding load condition.

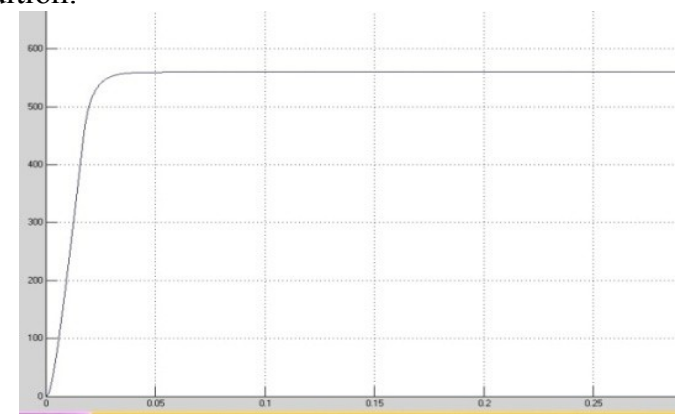

Fig. 6 Speed(rad/s) under no- load condition

The above Fig. 6 depicts the variation of speed with respect to time under no load condition. As soon as the motor reaches the steady state speed of $561.5 \mathrm{rad} / \mathrm{s}$, the starting current decreases to no-load current of $1.4 \mathrm{~A}$ (peak value), Te decreases to $0.028 \mathrm{Nm}$ and the trapezoidal back-EMF settles at 27Vshown in below fig.7. 


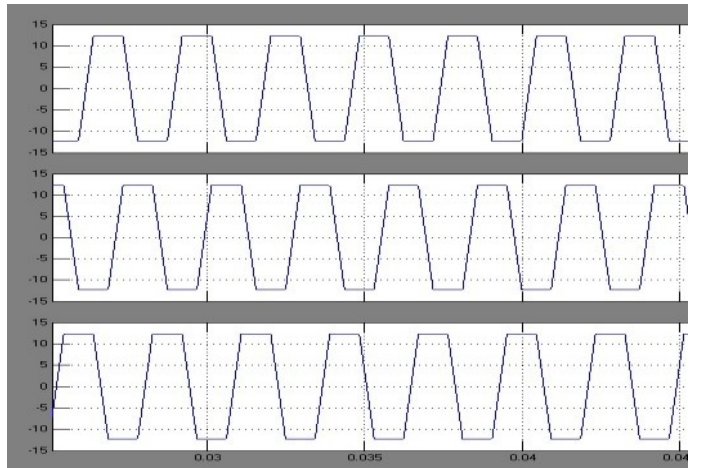

Fig. 7 Back- EMF under no- load condition

The Fig.7 shows the trapezoidal back-EMF produced in different phases of motor. The phase shift between each waveform is 120 degree and it is identical to the model graphs[1] and ideal waveforms of BLDC motor in Fig.4.

An electro-magnetic torque Te is developed as shown in Fig. 8 to start the motor from standstill. During the starting, motor draws high current hence the starting torque of the motor is high and settles at final value of $\mathrm{Te}=0.028 \mathrm{Nm}$.

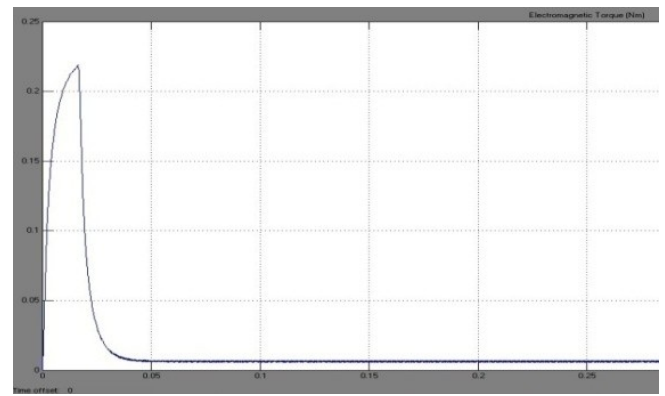

Fig. 8 Torque under no load condition

\section{Simulation under opposing loads:}

The speed characteristics of BLDC motor is shown in Fig. 9 under an applied load torque of TL= $0.44 \mathrm{Nm}$ and the final value of motor speed is $428.5 \mathrm{rad} / \mathrm{s}$. The current increases to $13.38 \mathrm{~A}$ from its no-load value of $1.4 \mathrm{~A}$ to meet extra load shown in Fig. 10 Once the load is removed all the parameters return to no-load condition state.

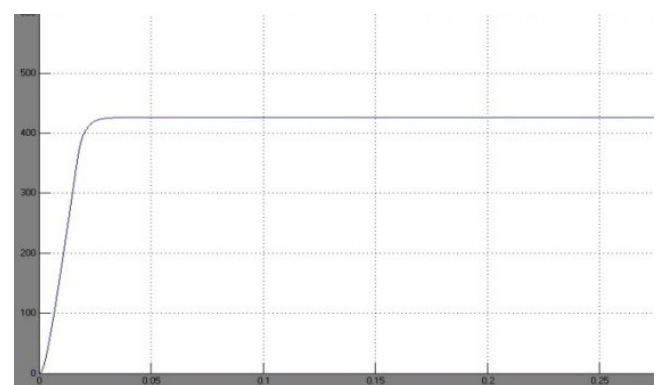

Fig. 9 Speed $(\mathrm{rad} / \mathrm{s})$ under opposing load $\left(\mathrm{T}_{\mathrm{L}}=0.44 \mathrm{Nm}\right)$

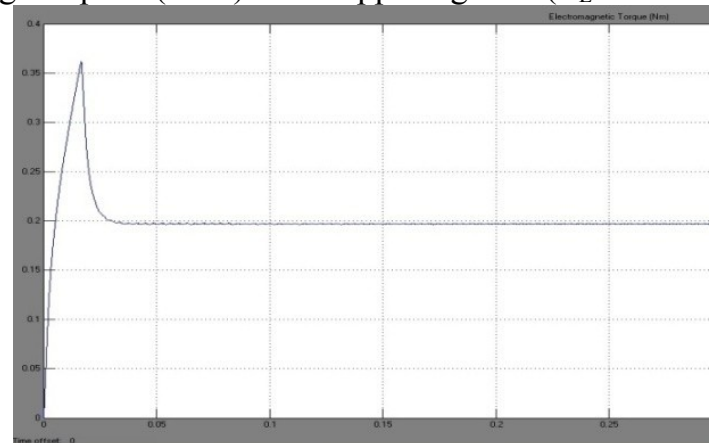

Fig. 10 Torque under opposing load $(\mathrm{TL}=0.44 \mathrm{Nm})$ 
From the Fig. 10 shows the torque characteristics under opposing load $\left(\mathrm{T}_{\mathrm{L}}=0.44 \mathrm{Nm}\right)$, electromagnetic torque developed by the motor in order to drive the load and friction torque is $\mathrm{Te}=0.468 \mathrm{Nm}$.

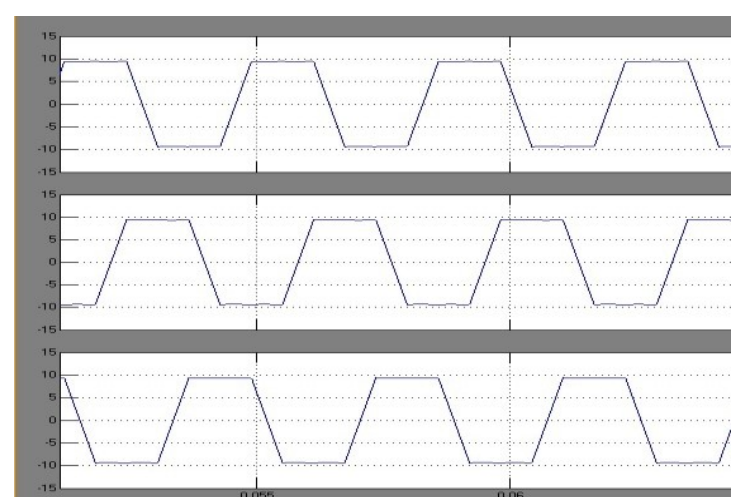

Fig.11 Back-EMF under opposing load $(\mathrm{TL}=0.44 \mathrm{Nm})$

As shown in Fig 11 back-EMFs of different phases under loaded condition are decreasing from it's no load value of $27 \mathrm{~V}$ to $18 \mathrm{~V}$. It is because of the decrement in the speed of the motor as back-EMF is directly related to the speed.

\section{Simulation under aiding loads:}

The speed characteristics of BLDC motor is shown in Fig. 12 under an applied load torque of TL= $0.22 \mathrm{Nm}$ and the final value of motor speed is $650.6 \mathrm{rad} / \mathrm{s}$.

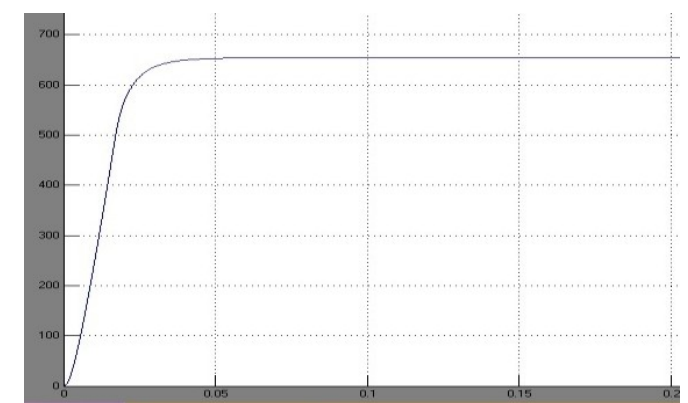

Fig. 12 Speed $(\mathrm{rad} / \mathrm{s})$ under aiding load $\left(\mathrm{T}_{\mathrm{L}}=-0.22 \mathrm{Nm}\right)$

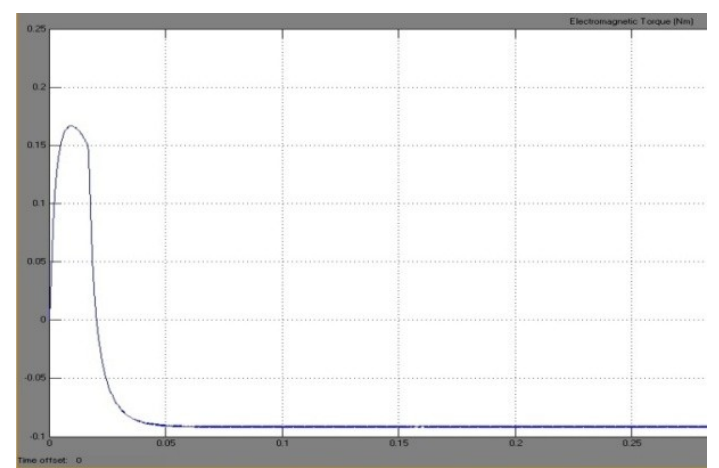

Fig. 13 Torque under aiding load $\left(\mathrm{T}_{\mathrm{L}}=-0.22 \mathrm{Nm}\right)$

Under the aiding load condition the electro-magnetic torque developed is $T_{e}=-0.165 \mathrm{Nm}$ in order to meet the frictional torque and load of $T_{L}=-0.22 \mathrm{Nm}$. 


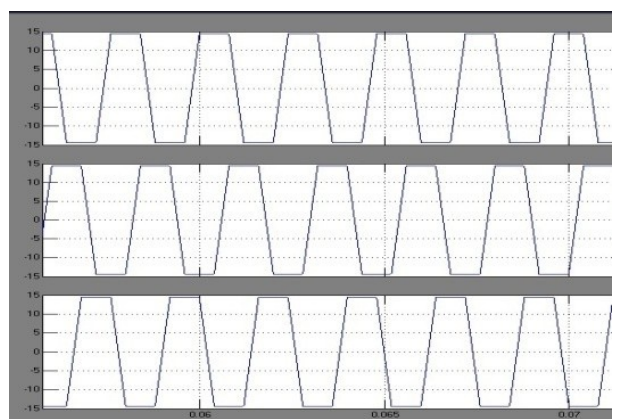

Fig.14 Back-EMF under aiding load $\left(\mathrm{T}_{\mathrm{L}}=-0.22 \mathrm{Nm}\right)$

When the BLDC motor is subjected to aiding load of $\mathrm{T}_{\mathrm{L}}=-0.22 \mathrm{Nm}$ its back-EMF in all its phases are increased to $30 \mathrm{~V}$ peak to peak, which is more than the applied de voltage of $28 \mathrm{~V}$. This shows that BLDC motor under the application of aiding load is acting like a generator and this increment in the back-EMF is due to the rise in speed.

Simulations have also been done under various opposing load conditions. The changes in speed and electromagnetic torque for various load conditions are tabulated. also tabulated.

The practical experimental set up of BLDC motor is shown in below fig. 15 and the practical values are

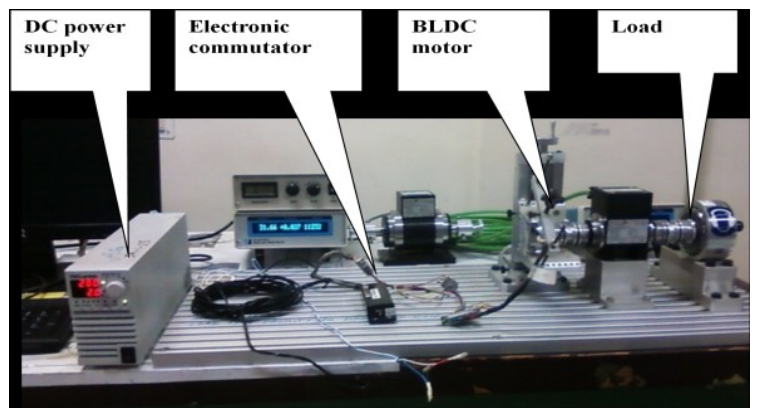

Fig. 15 Dynamometer type load test set up of BLDC Motor

\begin{tabular}{|c|c|c|c|c|c|c|}
\hline $\begin{array}{c}\text { S.n } \\
\text { o }\end{array}$ & $\begin{array}{c}\text { Load } \\
\text { torque } \\
(\mathrm{N}-\mathrm{m})\end{array}$ & $\begin{array}{c}\text { Speed } \\
(\mathrm{Rpm})\end{array}$ & $\begin{array}{c}\text { Current } \\
(\mathrm{amp})\end{array}$ & $\begin{array}{c}\text { Output } \\
\text { Power } \\
(\mathrm{W})\end{array}$ & $\begin{array}{c}\text { Input } \\
\text { Power } \\
(\mathrm{W})\end{array}$ & $\begin{array}{c}\text { Efficienc } \\
\mathrm{y}(\%)\end{array}$ \\
\hline 1 & 0.02 & 11560 & 1.9 & 24.19 & 53.2 & 45.5 \\
\hline 2 & 0.1 & 8992 & 5.2 & 94.06 & 145.6 & 64.6 \\
\hline 3 & 0.15 & 7896 & 7.2 & 123.17 & 201.6 & 61.1 \\
\hline 4 & 0.2 & 6972 & 8.9 & 145.85 & 249.2 & 58.52 \\
\hline
\end{tabular}

Table 4 Observations of BLDC motor under Opposing Load Condition

\section{Conclusion:}

Modeling of a BLDC motor is done with all its internal blocks and electronic commutator. Simulation is carried out for two types of loading: opposing and aiding. Aiding load shows generative action of the BLDC machine. Opposing load test is carried out on a lab model BLDC motor and the results are fairly matching with the simulation results. As practical testing of an aiding load on a motor is not possible with the available set up, the simulation results can be taken as its performance for further analysis of this motor.

\section{References:}

[1]. R.Krishnan and A. J. Beutler, "Performance and design of an axial field permanent magnet synchronous motor servo drive," in Proc.IEEE IAS Annu. Meeting, pp. 634-640, 1985.

[2]. M. Lajoie-Mazenc, C. Villanueva, and J. Hector, "Study and implementation of a hysteresis controlled inverter on a permanent.

[3]. "Modeling of BLDC Motor with Ideal Back-EMF for Automotive Applications", Proceedings of the World Congress on Engineering, July 2011.

[4]. "BLDC motor modeling and control- a MATLAB / SIMULINK implementation", Master Thesis in Electrical Power Engineering, May 2005.

[5]. "Simulation of Four Quadrant Operation \& Speed Control of BLDC Motor on MATLAB / SIMULINK", IEEE Region 10 Conference, Nov 2008.

[6]. Microchip Technology Inc: "AN885 - Product brief and specification”

[7]. "Fundamental of Electric drives" by G.K.Dubey

[8]. "Electrical Machines" by I.J.Nagrath and D.P.Kothari.

[9]. "Theory and Performance of Electric Machines" by J.B.Gupta

[10]. http://en.wikipedia.org/wiki/Brushless DC electric motor. 